\title{
Non-neoplastic Lesions among Lateral Neck Mass Specimens in a Tertiary Care Center: A Descriptive Cross-sectional Study
}

\author{
Rachana Dhakal, ${ }^{1}$ Ramesh Makaju, ${ }^{1}$ Monika Pokharel, ${ }^{2}$ Dipika Basnet,, Mukta Singh Bhandari ${ }^{3}$ \\ 'Department of Pathology, Dhulikhel Hospital, Kathmandu University School of Medical Sciences, Dhulikhel, \\ Kavre, Nepal, 'Department of Otorhinolaryngology, Dhulikhel Hospital, Kathmandu University School of \\ Medical Sciences, Dhulikhel, Kavre, Nepal, ${ }^{3}$ Department of Community Medicine, Kathmandu University School \\ of Medical Sciences, Dhulikhel, Kavre, Nepal.
}

\section{ABSTRACT}

Introduction: Lateral neck masses present clinically as neoplastic or non-neoplastic lesions of lymph nodes, salivary glands, and thyroid. Non-neoplastic lesions, if evaluated timely, may not transform into malignancy thus reducing clinical burden. A cytomorphological study using fine needle aspiration is a reliable method for the diagnosis of such masses. The aim of this study was to find out the prevalence of non-neoplastic lesions of lateral neck mass specimens received in the Department of Pathology in a tertiary care center.

Methods: This descriptive cross-sectional study was carried out in the Department of Pathology among lateral neck mass specimens of a tertiary care center from January 2019 to December 2020 after obtaining ethical approval from the Institutional Review Committee (Reference no: 155/19). A convenience sampling method was used and data analysis was done in Microsoft Excel 2019. Point estimate at 95\% Confidence Interval was calculated along with frequency and proportion for binary data.

Results: Out of 300 lateral neck mass specimens, non-neoplastic lesions were found in $246(82 \%)$ (77.7-86.3 at 95\% Confidence Interval). The involvement of lymph nodes in $117(47.6 \%)$ was the most common finding followed by thyroid 112 (45.5\%). Among non-neoplastic lesions, the cytomorphological features of benign nodular goiter $93(37.8 \%)$ was the most common lesion followed by reactive lymphoid hyperplasia 73 (29.7\%).

Conclusions: The study showed that the prevalence of non-neoplastic lesions was similar to that of other national and international studies.

Keywords: cytology; lymph node; thyroid gland.

\section{INTRODUCTION}

Lateral neck mass is one of the common clinical problems which have a wide pathologic spectrum. ${ }^{1}$ It can be congenital or acquired, neoplastic, or nonneoplastic. These can frequently present as enlarged lymph nodes which can be due to metastatic or inflammatory causes, thyroid disorders, or salivary gland tumors. Other causes could be branchial cyst, thyroglossal cyst, epidermal cyst, or soft tissue tumor. ${ }^{2}$

The clinical evaluation of these lateral neck masses is difficult because of the diversity of lesions. Hence, earlier evaluation of lateral neck masses with cytomorphological study avoids unnecessary surgeries in non-neoplastic or inflammatory conditions.
The objective of this study was to find out the prevalence of non-neoplastic lesions among lateral neck mass specimens received in the Department of Pathology, Dhulikhel Hospital- Kathmandu University Hospital (DH-KUH).

\section{METHODS}

A descriptive cross-sectional study was conducted in the Department of Pathology in a tertiary care center

Correspondence: Dr. Rachana Dhakal, Department of Pathology, Dhulikhel Hospital, Kathmandu University School of Medical Sciences, Dhulikhel, Kavre, Nepal. Email: sigdelrachana@gmail.com, Phone: +977-9841777944. 
from January 2019 to December 2020. Ethical approval was taken from the Institutional Review Committee of DH-KUH (Reference no: 155/19). In this study, all the patients attending the Department of Pathology, DH$\mathrm{KUH}$ in the study period having fine needle aspiration cytology (FNAC) of lateral neck masses were included. Convenience sampling was done and the sample size was calculated as,

$\mathrm{n}=\mathrm{Z}^{2} \times \mathrm{p} \times(1-\mathrm{p}) / \mathrm{e}^{2}$

$=(1.96)^{2} \times(0.5) \times(1-0.5) /(0.1)^{2}$

$=96$

Where,

$\mathrm{n}=$ minimum required sample size

$\mathrm{Z}=1.96$ at $95 \%$ Confidence Interval $(\mathrm{Cl})$

$p=$ prevalence, $50 \%$, for maximum sample size

$q=1-p$

$e=$ margin of error, $10 \%$

Taking a $10 \%$ non-response rate, the sample size was 106. After clinical examination, informed consent was obtained from patients. Under aseptic precautions, FNAC was done using a 22-24 gauge needle fitted to a $10 \mathrm{ml}$ disposable syringe. After immobilizing the target swelling, multiple passes were given to get sufficient material. Smears were prepared and stained with May Grunwald Giemsa (MGG) and Papanicolaou (PAP) stains. The Ziehl Neelsen (ZN) stain for Acid Fast Bacilli (AFB) was done in those cases, where clinically suspected as tuberculosis (TB), and also in those cases where purulent or cheesy material was aspirated.
The cytological features evaluated included cellularity (scanty, moderate, and high), cell arrangement, nuclear and cytoplasmic characteristics, and background elements. The cases were analyzed by the primary investigator. Inadequate samples were not included in the study.

The data were collected using proforma consisting of demographic characteristic and cytomorphological variables. The stained slides were examined under a light microscope by the primary investigator. The data were analyzed using Microsoft Excel 2019. Point estimate at $95 \%$ Confidence Interval was calculated along with frequency and proportion for binary data.

\section{RESULTS}

Out of 300 specimens collected in the study, the prevalence of non-neoplastic lesions was 246 (82\%) (77.7-86.3 at 95\% Confidence Interval).

The age of the patients ranged from 3 to 79 years including both male and female, the median age of occurrence being 39 years. Majority of the cases 37 $(31.6 \%)$ among lymph nodes were in the age group 2029 years, $33(29.5 \%)$ of the thyroid gland lesions were in the age group $50-59$ years and $4(23.5 \%)$ of the cases of salivary gland lesions were in the age group 10-19 years. Out of all cases, 11 (4.4\%) patients were seen in the age group below 10 years (Table 1 ).

\begin{tabular}{|llllllllll|}
\hline \multicolumn{7}{|l}{ Table 1. Age and site wise distribution of Non-neoplastic lesions of lateral neck masses. } \\
\hline Site & $\mathbf{0 - 9}$ & $\mathbf{1 0 - 1 9}$ & $\mathbf{2 0 - 2 9}$ & $\mathbf{3 0 - 3 9}$ & $\mathbf{4 0 - 4 9}$ & $\mathbf{5 0 - 5 9}$ & $\mathbf{6 0 - 6 9}$ & $\mathbf{7 0 - 7 9}$ & Total \\
& years & years & years & years & years & years & years & years & $\mathbf{n}(\%)$ \\
& $\mathbf{n}(\%)$ & $\mathbf{n}(\%)$ & $\mathbf{n}(\%)$ & $\mathbf{n}(\%)$ & $\mathbf{n}(\%)$ & $\mathbf{n}(\%)$ & $\mathbf{n}(\%)$ & $\mathbf{n}(\%)$ & \\
Lymph node & $9(3.7)$ & $15(6.1)$ & $37(15.0)$ & $15(6.1)$ & $14(5.7)$ & $11(4.5)$ & $10(4.1)$ & $6(2.4)$ & $117(47.6)$ \\
Thyroid & $1(0.4)$ & $2(0.8)$ & $14(5.7)$ & $14(5.7)$ & $23(9.3)$ & $33(13.4)$ & $18(7.3)$ & $7(2.8)$ & $112(45.5)$ \\
Salivary gland & $1(0.4)$ & $4(1.6)$ & $3(1.2)$ & $3(1.2)$ & $2(0.8)$ & $2(0.8)$ & $1(0.4)$ & $1(0.4)$ & $17(6.9)$ \\
Total & $11(4.5)$ & $21(8.5)$ & $54(21.9)$ & $32(13.0)$ & $39(15.9)$ & $46(18.7)$ & $29(11.8)$ & $14(5.7)$ & $246(100)$ \\
\hline
\end{tabular}

There were 87 (35.3\%) male and 159 (64.7\%) female patients. The incidence of lymph node lesion was significantly higher in females $62(53 \%)$ than males 55
$(47 \%)$. Similarly, in thyroid lesions, $89(79.5 \%)$ were females and $23(20.5 \%)$ were males. The incidence of salivary gland lesion was slightly higher in male 9 (53\%) (Table 2).

\begin{tabular}{|c|c|c|c|}
\hline Site & Male n (\%) & Female n (\%) & Total n (\%) \\
\hline Lymph node & 55 (47) & 62 (53) & $117(100)$ \\
\hline Thyroid & $23(20.5)$ & 89 (79.5) & $112(100)$ \\
\hline Salivary gland & $9(53)$ & $8(47)$ & $17(100)$ \\
\hline Total & 87 (35.3) & 159 (64.7) & $246(100)$ \\
\hline
\end{tabular}

The distribution of cytomorphological spectrum of nonneoplastic lesions of lateral neck masses result showed lymph nodes lesion $117(47.6 \%)$ as the predominant site of FNAC followed by thyroid lesions 112 (45.5\%) and salivary gland lesions 17 (6.9\%). Among 117 cases of lymph node lesions, reactive lymphoid hyperplasia
$73(29.7 \%)$ was the main cause of lymphadenopathy followed by tubercular lymphadenitis 29 (11.8\%) and nonspecific/ suppurative inflammatory lesions 15 $(6.1 \%)$. Out of 112 thyroid lesions, benign nodular goiter lesions were $93(37.8 \%)$ and lymphocytic thyroiditis (including Hashimoto's thyroiditis) 19 (7.7\%). Among 
$17(6.9 \%)$ salivary gland lesions, all the lesions were diagnosed as chronic sialadenitis (Table 3).

\begin{tabular}{|c|c|c|}
\hline Site & Lesion & $\begin{array}{l}\text { No. of cases } \\
n(\%)\end{array}$ \\
\hline \multirow[t]{3}{*}{$\begin{array}{l}\text { Lymph } \\
\text { node }\end{array}$} & $\begin{array}{l}\text { Reactive lymphoid } \\
\text { hyperplasia }\end{array}$ & $73(29.7)$ \\
\hline & Tubercular Lymphadenitis & $29(11.8)$ \\
\hline & Nonspecific /Suppurative & $15(6.1)$ \\
\hline \multirow[t]{2}{*}{ Thyroid } & $\begin{array}{l}\text { Benign Nodular Goiter } \\
\text { (Colloid Goiter) }\end{array}$ & 93 (37.8) \\
\hline & $\begin{array}{l}\text { Lymphocytic thyroiditis } \\
\text { (including Hashimoto's } \\
\text { thyroiditis ) }\end{array}$ & $19(7.7)$ \\
\hline $\begin{array}{l}\text { Salivary } \\
\text { Gland }\end{array}$ & Chronic sialadenitis & $17(6.9)$ \\
\hline Total & & $246(100)$ \\
\hline
\end{tabular}

\section{DISCUSSION}

Lateral neck mass is one of the challenging diagnostic problems to the clinician. Although surgical biopsy is the gold standard method of tissue diagnosis, FNAC has become one of the first line investigation method to evaluate the lateral neck masses. ${ }^{1} \mathrm{~A}$ lateral neck mass may suggest a wide range of entities in a differential diagnosis, including reactive, infectious, developmental, and neoplastic conditions. ${ }^{3}$

In the present study, cytomorphological features of 246 cases of non-neoplastic neck masses were analyzed. Maximum numbers of cases were observed in the age group of 20 to 29 years and 50 to 59 years respectively. Our study is similar to the study by Agrawal, et al. which showed female preponderance and similar age group distribution. ${ }^{4}$ Similarly, Soni, et al. observed the involvement of $66.15 \%$ female and $33.89 \%$ males which were similar to our study which constituted $35.3 \%$ male and $64.7 \%$ female. $^{5}$

Reactive lymphadenopathy may present as a tender, mobile swelling and should be considered in the context of a recent infection or regional injury. Resolution of the underlying infectious or inflammatory origin results in normalization of the node within weeks. ${ }^{6}$ In the various pathological spectrum of lymphadenopathies, reactive hyperplasia constituted the majority of the cases $(29.7 \%)$. The findings were similar to the study conducted by Agrawal et al. which constituted lymphoid hyperplasia as the predominant cause of lymphadenopathy. ${ }^{4}$

In the present study, tubercular lymphadenitis (11.8\%) was the other common lesion among lymph nodes.
Though the diagnosis of tuberculosis can be made by Enzyme Linked Immunosorbent Assay (ELISA) and Polymerase Chain Reaction (PCR) but these methods are very costly and are not available at many centers. ${ }^{7}$ Hence, FNA smears with ZN stain is the first line diagnostic technique. ${ }^{8}$ With the prompt diagnosis and treatment of tuberculosis morbidity and mortality can be reduced. ${ }^{9}$

Thyroid lesions are the commonly encountered lesion in the world and FNAC is a safe and cost-effective diagnostic modality in screening thyroid masses. In our study, among thyroid lesions, colloid goiter was the commonest lesion which constituted about $37.8 \%$ of cases. Rout, et al. also observed colloid goiter as the common thyroid swelling $(42.2 \%)$ in his study. ${ }^{10}$

In thyroid aspiration cytology, marked cellular smear is one of the common issues, where increased cellularity with loss of cohesion may be present in hyperplastic /adenomatous goiter, adenoma, or carcinoma. The importance of earlier diagnosis of thyroid lesion by using FNAC is that thyroiditis and colloid goiter can be managed with a conventional method, likewise, lymphomas and undifferentiated carcinomas may be managed with radiotherapy or chemotherapy. ${ }^{11}$ Hence, earlier diagnosis of such lesions through aspiration cytology prevents surgical intervention.

Chronic sialadenitis is one of the pitfalls in salivary gland cytopathology as the associated malignancy might not be aspirated which leads to a false- negative diagnosis. Besides, the presence of reactive cellular atypia might also lead to over diagnosis and patient might undergo unnecessary surgery. ${ }^{12,13}$ In this study, all the salivary gland lesions were diagnosed as chronic sialadenitis which accounted for $6.9 \%$ which was similar to findings from study by Manjula, et al. ${ }^{14}$

\section{CONCLUSIONS}

The prevalence of non-neoplastic lesion was high among the lateral neck masses with about four in five specimens being non-neoplastic. Benign nodular goiter was the most common cytomorphological findings in the thyroid gland. Reactive Iymphoid hyperplasia and chronic sialadenitis were the main lesions among lymph nodes and salivary gland respectively.

\section{ACKNOWLEDGEMENTS}

We are grateful to the Department of Pathology and Otorhinolaryngology, $\mathrm{DH}-\mathrm{KUH}$ for their constant support.

Conflict of Interest: None. 


\section{REFERENCES}

1. Johnson JT, Moskovitz JM. Fine-needle aspiration of neck masses [Internet]. Medscape. Manhattan: WebMD; [updated 2018 Sept 25; cited 2020 Nov 4]. Available from: http:// emedicine.medscape.com/. [Full Text]

2. Iacob A, Zazgyva A, Ormenisan A, Mezei T, Sin A, Tilinca M. Effectiveness of fine-needle aspiration cytology in the diagnosis of lateral cervical non thyroid tumors. Medicine (Baltimore). 2016 Aug;95(31):e4448. [PubMed | Full Text | DOI]

3. Ishar T, Gupta RK, Khajuria A. Role of FNAC in diagnosis of non-thyroidal head and neck lesions. JK Science. 2012 Jan;14(1):9-13. [Full Text]

4. Agrawal N, Sharma HS, Hansrajani V, Samadhiya M, Raghuwanshi V, Khandelwal P, et al. Study of cervical neck masses and role of fine needle aspiration cytology in Central India. AIMDR. 2017;3(3):EN19-22. [Full Text | DOI]

5. Soni S, Pippal SK, Yashveer B, Srivastava P. Efficacy of fine needle aspiration cytology in diagnosis of neck masses. world articles in ar, Nose and Throat; 4 Sep 2010 [cited Jan 12 2021];3(1); [about 4 screens]. Available from: https:// www.waent.org/archives/2010/Vol3-2/20100816-fna/ fine-needle-aspiration.htm. [Full Text]

6. Schwetschenau E, Kelley DJ. The adult neck mass. Am Fam Physician. 2002 Sep 1;66(5):831-8. [PubMed | Full Text]

7. Vimal S, Dharwadkar A, Chandanwale Shrish S, Verma $\mathrm{V}$, Khandelwal A. Fine needle aspiration cytology in the diagnosis of Tuberculous lymphadenitis and utility of Ziehl Neelsen stain benefits and pitfalls. Int J Med Res Rev. 2016;4(8):1466-75. [Full Text | DOI]

8. Pradhan A, Poudyal P, Upadhyaya P, Pokhrel
S. Cytomorphological spectrums in tuberculous lymphadenitis: understanding the stages of disease. Journal of BP Koirala Institute of Health Sciences. 2018;1(2):21-9. [Full Text | DOI]

9. Khan RA, Wahab S, Chana RS, Naseem S, Siddique S. Children with significant cervical lymphadenopathy: clinicopathological analysis and role of fine-needle aspiration in Indian setup. J Pediatr (Rio J). 2008 Sep-Oct;84(5):449-54. [PubMed | Full Text | | DOI]

10. Rout K, Ray CS, Behera SK, Biswal R. A comparative study of FNAC and histopathology of thyroid swellings. Indian J Otolaryngol Head Neck Surg. 2011 Oct;63(4):370-2. [PubMed | Full Text | DOI]

11. Handa U, Garg S, Mohan H, Nagarkar N. Role of fine needle aspiration cytology in diagnosis and management of thyroid lesions: a study on 434 patients. J Cytol. 2008;25(1):13-7. [Full Text]

12. Viswanathan $K$, Sung $S$, Scognamiglio T, Yang GCH, Siddiqui MT, Rao RA. The role of the Milan System for reporting salivary gland cytopathology: a 5-year institutional experience. Cancer Cytopathol. 2018 Aug;126(8):541-51. [PubMed | Full Text | DOI]

13. Rohilla M, Singh P, Rajwanshi A, Gupta N, Srinivasan R, Dey P, Vashishta RK. Three-year cytohistological correlation of salivary gland FNA cytology at a tertiary center with the application of the Milan system for risk stratification. Cancer Cytopathol. 2017 Oct;125(10):767-75. [PubMed | Full Text | $\underline{\mathrm{DOI}}]$

14. Manjula K, Prasad CSBR, Gayathri BN, Kumar H. Cytomorphological study of lateral neck swellings. J Clin Diagn Res. 2011;5(5):1016-9. [Full Text] 